\title{
SPH 法による異種金属接合板の衝撃問題の解析*
}

\author{
楯岡将規 ${ }^{* 1}$, 小原治樹 ${ }^{* 2}$, 小山彰規 ${ }^{* 1}$, 釣谷航世 ${ }^{* 1}$, 笹木亮 ${ }^{* 2}$

\section{Impact Simulation of Plate Composed of Different Materials by SPH Method} \\ Masaki TATEOKA, Haruki OBARA*2, Akinori KOYAMA, \\ Kousei TURIYA and Tohru SASAKI \\ $*^{2}$ Department of Mechanical and Intellectual Systems Engineering, University of Toyama, \\ 3190 Gofuku, Toyama City 930-8555, Japan
}

In this study, a method of analyzing the dynamic behavior of an elastic object composed of different materials is proposed for smoothed particle hydrodynamics, SPH. In this method, the acceleration of a particle is calculated using the proposed equation, the relaxation equation for momentum, but the stresses are obtained using normalized relaxation equations for stresses, which are not sensitive to the edge effect of SPH caused by the lack of particles around the free surface. This hybrid method makes it possible not only to treat elastic multiphase materials without division into the individual phases, but also to save on the effort of searching particles and setting boundary conditions to them at the free surface. Numerical results are obtained for the propagating stress and strain distribution caused by an impact on a two-dimensional plate composed of different materials.

Key Words : SPH, Multi Phase Problem, Edge Effect, Elastic, Relaxation Equation

\section{1. 緒言}

Monaghan や(1)Libersky ら ${ }^{(2)}$ が開発した Smoothed Particle Hydrodynamics（SPH 法）は，格子を用いる解析法とは 異なり，解析対象を粒子の集合として扱う。この方法は，格子相互位置関係を必要としないためプログラムが単 純であり, 自由表面の判定などを必要としないため破砕・飛散問題や多相流体問題, 連成問題などが扱いやすい. 例えば，S. Hiermaier ら (3)は宇宙船隔壁に Debris が衝突する場合の破壊，飛散問題を扱っている．しかし，一般工 学問題に適用する場合に，物性值の大きく異なる物質が共存するとき，接触境界にまたがって 2 物質を同時に解 析すると，その接触境界面近傍において数值異常が生じ計算不能になることがある。これを本論文では 2 相境界 問題と呼ぶ. 既報(4), (5)で我々は, 非粘性流体の 2 相境界問題を解決するために, 異なる物質の境界面にまたがっ て計算できる緩和計算式と名付けた計算式を提案し, 密度が 1000 倍異なる空気 - 水の 2 相流体中の圧力伝播につ いて解析例を示した。本論文では物性值が大きく異なる物質の破壊, 飛散を伴う相互作用や, 流体一固体連成問 題を扱う上で基礎となる, 弾性体のための緩和計算式を提案する.また, SPH 法では自由表面近傍で粒子が欠落 するため, 端末効果と呼ばれる数值異常が生じる.この数值異常は流体の場合に較べ固体応力の計算で顕著に表 れる.ここでは圧力や応力を粒子久落に依存しないNSPH 法で計算し，加速度を緩和計算式で計算するハイブリ ットSPH 計算法を提案する。この計算法は多相問題における自由表面の取扱いを容易にする。この計算法を，異 種金属を接合した薄板の衝撃問題に適用した結果を述べる.

* 原稿受付 2010 年 10 月 12 日

*1 学生員, 富山大学工学部

*2 正員, 富山大学（广930-8555 富山県富山市五福 3190)

E-mail: obarah@eng.u-toyama.ac.jp 


\section{SPH法}

SPH 法の数学的根拠は，滑らかな関数 $f$ を平均化した次式である.

$$
<f(X)>=\int f\left(X^{\prime}\right) W\left(X^{\prime}-X, \tilde{h}(X)\right) d X^{\prime}
$$

ここで，Wは空間積分值が 1 となるガウス関数やBスプライン関数， る. 離散形では $i$ 粒子の $f$ の平均值及びその導関数を,

$$
\begin{aligned}
& <f(X)>_{i}=\sum_{j=1}^{N} f_{j} \frac{m_{j}}{\rho_{j}} W^{i}\left(X_{i}-X_{j}, \tilde{h}\right) \\
& <\frac{\partial f(X)}{\partial X}>_{i}=-\sum_{j=1}^{N} f_{j} \frac{m_{j}}{\rho_{j}} \frac{\partial W^{i}\left(X-X_{i}, \tilde{h}\right)}{\partial X}{ }_{j}
\end{aligned}
$$

のように求める. $\rho$ は密度, $m$ は粒子質量である. 加算は $i$ 粒子を中心とする支持領域ないし, 影響領域内にある $j$ 粒子について行う。一般に $W$ には $j$ 点を中心とする核関数が用いられるが，ここでは前報 ${ }^{(4),(5)}$ に述べたように, 数值誤差を減ずるため, $i$ 点を中心とする核関数 $W^{i}$ を用いている. $\left(\partial W^{i} / \partial X\right)_{j}$ は $i$ 点を中心とする核関数の $j$ 点に

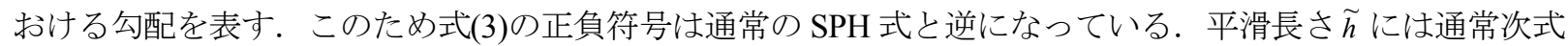

$$
\tilde{h}=\eta(m / \rho)^{\frac{1}{3}} \text {, 通常 } \eta=1
$$

が用いられる.

\section{3. 弾性体の構成方程式と通常の SPH 計算式}

\section{$3 \cdot 1$ 構成方程式}

弾性体の運動方程式は次式で与えられる.

$$
\frac{d v^{\alpha}}{d t}=\frac{1}{\rho} \frac{\partial \sigma^{\alpha \beta}}{\partial x^{\beta}}
$$

ここで， $v, \rho$ 及び $\sigma$ はそれぞれ速度，密度及び応力を示す．上添え字の $\alpha, \beta=1,2,3$ は座標方向を表す．本論文では 応力速度，歪み速度を用いる．応力速度は次式で与えられる．

$$
\frac{d \sigma^{\alpha \alpha}}{d t}=A^{\alpha \beta} \frac{d \varepsilon^{\beta \beta}}{d t}, \quad \frac{d \sigma_{\alpha \neq \beta}^{\alpha \beta}}{d t}=G \frac{d \varepsilon^{\alpha \beta}}{d t}
$$

ここで $G$ は横弾性係数である. $\varepsilon$ は歪みで, 歪み速度は次式で与えられる.

$$
\frac{d \varepsilon^{\alpha \beta}}{d t}=\frac{1}{2}\left(\frac{\partial v^{\beta}}{\partial x^{\alpha}}+\frac{\partial v^{\alpha}}{\partial x^{\beta}}\right)
$$

$A$ は材料による定数で, ヤング率 $E$, ポアソン比 $v$ を用い,

$$
A_{\alpha=\beta}^{\alpha \beta}=E 1=\frac{(1-v) E}{(1+v)(1-2 v)}, \quad A_{\alpha \neq \beta}^{\alpha \beta}=E 2=\frac{v E}{(1+v)(1-2 v)}
$$

で与えられる.

\section{$3 \cdot 2$ 通常のSPH 計算式}

Liu ら ${ }^{(6)}$ によれば，通常, SPH では加速度計算には次の式が用いられる.

$$
\frac{d v_{i}^{\alpha}}{d t}=-\sum_{j} m_{j} \frac{\sigma_{j}^{\alpha \beta}+\sigma_{i}^{\alpha \beta}}{\rho_{i} \rho_{j}} \frac{\partial W^{i}}{\partial x^{\beta}},
$$

または 


$$
\frac{d v_{i}^{\alpha}}{d t}=-\sum_{j} m_{j}\left(\frac{\sigma_{i}^{\alpha \beta}}{\rho_{i}^{2}}+\frac{\sigma_{j}^{\alpha \beta}}{\rho_{j}^{2}}\right) \frac{\partial W^{i}}{\partial x^{\beta}}{ }_{j}
$$

また歪み速度計算には次式が用いられる。

$$
\begin{aligned}
& \frac{d \varepsilon_{i}^{\alpha \beta}}{d t}=-\frac{1}{2} \sum_{j} \frac{m_{j}}{\rho_{j}}\left(v_{i j}^{\alpha} \frac{\partial W^{i}}{\partial x_{i}^{\beta}}+v_{i j}^{\beta} \frac{\partial W^{i}}{\partial x_{i}^{\alpha}}\right) \\
& \text { ここで, } \quad v_{i j}=v_{j}-v_{i}
\end{aligned}
$$

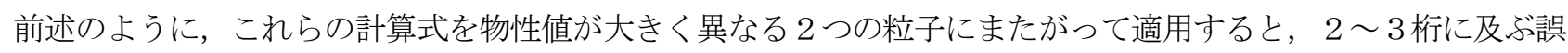
差を生ずる.

\section{4. 弾性体の緩和計算式}

物性值の大きく異なる 2 つの物体が分離せずに移動するとき，境界面の左右で加速度や応力増加速度が連続と なるが，このときこれを満たすためには速度勾配や応力勾配についての条件式が必要となる. 例えば $x$ 方向 1 次 元の運動で $x$ 方向の途中に物質 $\mathrm{A}, \mathrm{B}$ の境界面があるとき, $u$ を $x$ 方向速度とすれば, 界面左右の加速度は同一だ から応力勾配について次の関係式が成り立つ.

$$
\frac{d u}{d t}=-\left.\frac{1}{\rho_{\mathrm{A}}} \frac{\partial \sigma_{x}}{\partial x}\right|_{\mathrm{A}}=-\left.\frac{1}{\rho_{\mathrm{B}}} \frac{\partial \sigma_{x}}{\partial x}\right|_{\mathrm{B}}
$$

緩和計算式はこのような条件下で境界面にまたがって計算したときに, 応力や加速度が異常な值にならないよう に構成する。

前報 ${ }^{(4)}$ の非粘性流体のための緩和計算式の導出法を参考に, 一般化した緩和計算式を導く. 最初に 1 次元で $x$ 方向に境界面がある場合を考える。一般に SPH 法では次の計算形式が用いられる.

$$
\begin{gathered}
g_{i}=\sum_{j} \frac{m_{j}}{\rho_{j}} D_{j}\left(f_{j}-f_{i}\right) \frac{\partial W^{i}}{\partial x} j_{j} \\
g_{i}=D_{i} \sum_{j} \frac{m_{j}}{\rho_{j}}\left(f_{j}+f_{i}\right) \frac{\partial W^{i}}{\partial x} j_{j}
\end{gathered}
$$

式(9),(11)に見られるように，式(13)は主に応力や歪みの計算に用いられ，式(14)は加速度計算に用いられる， 1 次元応力計算では式(13)の $g$ が $d \sigma_{x} / d t, D$ がヤング率 $E, f$ が速度 $u$ であり, 加速度の場合は式(14)の $g$ が加速度, $D$ が-1/p, fが $\sigma_{x}$ に対応する. ここで 2 物質が分離せずに移動し, 式(12)のように境界面の左右で $D \partial f / \partial x$ が連続 であるとする. また, $i, j$ 粒子が異なる物質の時, 境界位置を $x *$ とし, 式(13)を $i, j$ 粒子の寄与に分けて,

$$
g_{i}=\sum_{j} \frac{m_{j}}{\rho_{j}}\left[D_{j}\left(f_{j}-f_{x^{*}}\right)+D_{i}\left(f_{x^{*}}-f_{i}\right)\right] \frac{\partial W^{i}}{\partial x}{ }_{j}
$$

とする. 境界面左右の勾配の連続条件から，

$$
D_{j} \frac{f_{j}-f_{x^{*}}}{x_{j}-x^{*}}=D_{i} \frac{f_{x^{*}}-f_{i}}{x^{*}-x_{i}}
$$

が成り立つから， $i, j$ 粒子の中間位置に境界面 $x$ *があると仮定すれば，次式が成り立つ.

$$
D_{j}\left(f_{j}-f_{x^{*}}\right)=D_{i}\left(f_{x^{*}}-f_{i}\right)
$$

式(17)から $f_{x^{*}}$ を求め式(15)に代入すると，

$$
g_{i}=2 \sum_{j} \frac{m_{j}}{\rho_{j}} \frac{D_{i} D_{j}}{D_{i}+D_{j}}\left(f_{j}-f_{i}\right) \frac{\partial W^{i}}{\partial x}
$$

が得られる．同様に，式(14)を次のように変形し， 


$$
g_{i}=\sum_{j} \frac{m_{j}}{\rho_{j}}\left[2 D_{i} f_{i}+D_{i}\left(f_{j}-f_{i}\right)\right] \frac{\partial W^{i}}{\partial x}
$$

式(17)を仮定して $f_{x^{*}}$ 求め, 式(19)に代入すれば

$$
g_{i}=2 D_{i} \sum_{j} \frac{m_{j}}{\rho_{j}} \frac{D_{i} f_{i}+D_{j} f_{j}}{D_{i}+D_{j}} \frac{\partial W^{i}}{\partial x}
$$

が得られる. 式(18), (20)は， $i, j$ 粒子の中間位置に境界面を仮定したため，同一径の $i, j$ 粒子が隣接している場合 以外は正しくないが，密度や音速が大きく異なる水一空気の場合，従来の計算式の誤差が 3 桁程度であるのに対 し, 数\%の誤差である ${ }^{(4)}$. また, $\widetilde{h}$ をさくすると誤差は減少する. 式(18), (20)は $g$ が 1 次元 1 变数 $f$ に依存する 場合の緩和計算式であるが，3 次元多変数に拡張すれば，式(18), (20)の代わりに次式となる.

$$
\begin{gathered}
g_{i}^{\alpha}=2 \sum_{j} \frac{m_{j}}{\rho_{j}} \frac{D_{i} D_{j}}{D_{i}+D_{j}}\left(f_{j}^{\alpha \beta}-f_{i}^{\alpha \beta}\right) \frac{\partial W^{i}}{\partial x^{\beta}}{ }_{j} \\
g_{i}^{\alpha}=2 D_{i} \sum_{j} \frac{m_{j}}{\rho_{j}} \frac{D_{i} f_{i}^{\alpha \beta}+D_{j} f_{j}^{\alpha \beta}}{D_{i}+D_{j}} \frac{\partial W^{i}}{\partial x^{\beta}}{ }_{j}
\end{gathered}
$$

式(21), (22)は 1 次元の式を単純に 3 次元に拡張したものであるが，境界面に垂直な方向だけでなく，直角な方向 に適用した場合にも，従来の式に較べ数值異常が緩和されることを確認している.

式(21), (22)を式(5), (6), (7)に適用すると次の 3 次元の加速度, 応力の緩和計算式が得られる.

$$
\begin{gathered}
\frac{d v_{i}^{\alpha}}{d t}=-\frac{2}{\rho_{i}} \sum_{j} \frac{m_{j}}{\rho_{j}} \frac{\rho_{i} \sigma_{j}^{\alpha \beta}+\rho_{j} \sigma_{i}^{\alpha \beta}}{\rho_{i}+\rho_{j}} \frac{\partial W^{i}}{\partial x^{\beta}}{ }_{j} \\
\frac{d \sigma_{i}^{\alpha \alpha}}{d t}=-2 \sum_{j} \frac{m_{j}}{\rho_{j}}\left\{\frac{E 1_{i} E 1_{j}}{E 1_{i}+E 1_{j}} v_{i j}^{\alpha} \frac{\partial W^{i}}{\partial x_{\alpha}}+\frac{E 2_{i} E 2_{j}}{E 2_{i}+E 2_{j}}\left(v_{i j}^{\beta} \frac{\partial W^{i}}{\partial x_{\beta}}\right)_{j \neq \alpha}\right\} \\
\frac{d \sigma_{i, \alpha \neq \beta}^{\alpha \beta}}{d t}=-2 \sum_{j} \frac{m_{j}}{\rho_{j}} \frac{G_{i} G_{j}}{G_{i}+G_{j}}\left(v_{i j}^{\beta} \frac{\partial W^{i}}{\partial x^{\alpha}}+v_{i j}^{\alpha} \frac{\partial W^{i}}{\partial x^{\beta}}\right)
\end{gathered}
$$

実際の計算では，核関数にはガウス関数を用い， $m_{j} / \rho_{j}\left(\partial W^{i} / \partial x\right)_{j}$ の計算には，誤差を減ずるために既報(4)で述べた $\partial W^{i} / \partial x$ を各 $j$ 粒子について積分した後に加算する方法を用いている.

\section{5. ハイブリッドSPH法}

SPH 法の端末効果問題は，自由表面近傍で粒子が久落し，物理量や物理量の勾配の平均值が正しい值にならな いために発生する．この対策として自由表面に物理量を与え半陰的に解析する方法がある。また粒子欠落に影響 されないメッシュフリー法, 例えば Randles $ら^{(7)}$ が提案した SPH 計算式を正規化する NSPH 法や, 移動最小自乗 近似法（MLS 近似）を用いる方法が考えられる. MLS 近似は仮定した計算式と各点の值との自乗誤算に重み関 数を掛けた合計值が最小になるように計算式の係数などを求める方法であるが，ここでは計算に必要な，2物質 にまたがった式を構成するに至らなかったので適用しない. NSPH 法は粒子の欠落により生じる端末効果の影響 を除くため, 物理量 $f$ の 1 次勾配を次式のように正規化して求める.

$$
\left\langle\frac{\partial f}{\partial x}\right\rangle_{i}=\frac{\sum_{j} \frac{m_{j}}{\rho_{j}}\left(f_{j}-f_{i}\right) \frac{\partial W^{i}}{\partial x_{j}}}{\sum_{j} \frac{m_{j}}{\rho_{j}}\left(x_{j}-x_{i}\right) \frac{\partial W^{i}}{\partial x_{j}}}
$$

物理量の評価法としては，平均值を用いる方法と $f_{i}$ を用いる方法が考えられるが，ここでは後者の方法を用い る. しかし, 半陰的な解析法も含め, これらの計算法では自由表面の場合には自由表面粒子を規定し, 物理量を 与える必要がある. これは, 複雑な問題ではやっかいである. 本来 SPH 法はそのような操作を必要としないこと も大きな特徵であるから，この性質を生かして端末効果を避ける計算方法を検討した。 
SPH 法では端末効果があると，加速度の数值異常は粒子を自由表面外に押し出すように働く。これによって応 力が負となり粒子が引き戻されれば, 自然に自由表面の応力が 0 となり, 自由表面の条件が満たされる. また自 由表面を判定する必要もなくなる。しかし，応力は精度良く計算する必要がある．そこで応力を NSPH 法で計算 し，加速度を SPH 法で計算する方法が考えられる．この計算法を，ここではハイブリットSPH 法と呼ぶ.

2 物質にまたがった応力計算を行うとき，2つの方法が考えられる．1つは応力の緩和計算式(24), (25)を正規 化して用い，2つの金属にまたがった応力計算を行う方法（以下，ハイブリッドSPH 法 I と呼ぶ）で，もう一つ は緩和計算式ではなく通常の応力計算式を正規化した式を用い，金属毎に別に計算する方法（以下，ハイブリッ ド SPH 法II と呼ぶ）である. 後者の方法では計算される応力值は異種金属の存在に影響されないが，2つの金属 にまたがった加速度計算のときに干渉現象が表現される.

\section{6. 数值解析}

\section{$6 \cdot 1 \quad 2$ 次元弾性板衝撃問題}

1 次元の棒と棒を衝突させた場合, 棒中にはステップ状の圧縮応力波が伝播し, 応力值 $\sigma$ は棒内部の物質の移 動速度 $u$ と,

$$
\sigma=\rho C u
$$

の関係がある(8)． $\rho$ は密度， $C$ は音速を示す．ここではこの問題を 2 次元に拡張した薄い平板の軸方向衝撃圧縮 問題について, 従来の SPH 法とハイブリッド SPH 法, 及び有限要素法解析ソフト MSC.Marc2007 を用いて平面 応力状態での解析を行い, 比較した. この場合は単一物質なのでハイブリッド SPH 法 I と II の区別はない. 図 1 に 2 次元平板弾性体モデルを示寸. SPH 法では上部 3 層固定粒子に一様な一定速度 $v_{0}=0.5[\mathrm{~m} / \mathrm{s}]$ 与え, $y$ 方向に 圧縮する. 底部は固定され, 側面は自由表面である. 板厚 $z$ 方向の応力は 0 である. 粒子数は $51 \times 203$ とした. 板材は鉄とした．FEM では 2 次元平板モデルで $20 \times 80$ の 4 辺形要素を用い完全積分としたが，端面の速度で境 界条件を与えることができなかったため, 端面に式(27)で定まる一様で一定の軸方向応力值 $2.01 \times 10^{7}[\mathrm{~Pa}]$ 与皇 た. 1 軸負荷の場合は速度で与えても応力で与えても両者の負荷条件は等価である. 2 次元の場合, SPH 法では 3 層固定粒子に接する粒子の横方向移動は自由としているが， 3 層固定粒子の影響を受けるため，厳密には SPH 法の計算は FEM の計算と同一でないと考えられる。しかし，以降の結果に見られるように両者に大きな差異は 観察されない.

図 2 に従来のSPH 法の計算式を用い, 修正 Euler 法を用いて陽解法で解析した場合の応力 $\sigma_{y}$ の分布を示す. ク ーラン数は 1 とした。自由表面の応力值は与えていない. また，人工粘性は用いていない．粒子久落によって端 末効果が発生し, 大きな数値乱れのために途中で解析不能となった.

図 3 にハイブリットSPH 法を用いて陽解法で解析した結果を示し, 図 4 にMarc を用いて解析した結果を示す. 人工粘性は用いていない，表題中の時間は衝撃開始からの経過時間である. 図 3 と図 4 ではほぼ同じ結果が得ら れているが，図 3 では自由表面に粒子毎の応力振動が見られる。これは自由表面から粒子が飛び出そうとして引 き戻されて振動するためと考えられる. 緩やかな振動は板の幅方向の振動によって発生したと考えられる. 1 次 元衝撃では理論上はステップ状の応力分布となるが, 本解析の 2 次元の平均応力值は 1 次元衝撃の理論応力值と

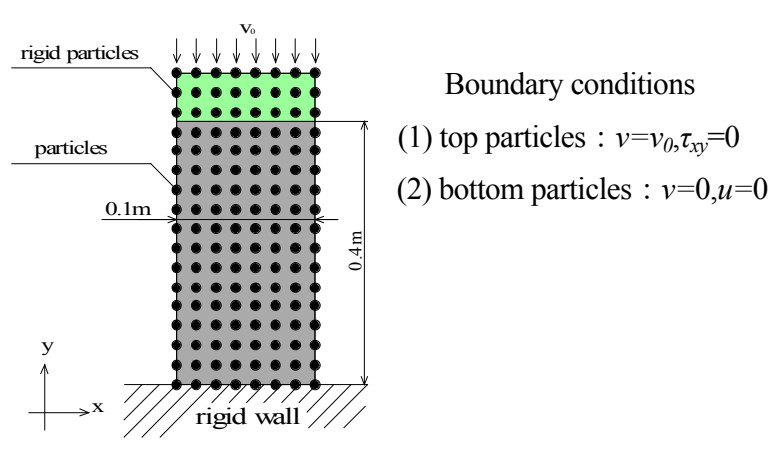

Fig.1 Impact model of 2dimensional thin plate

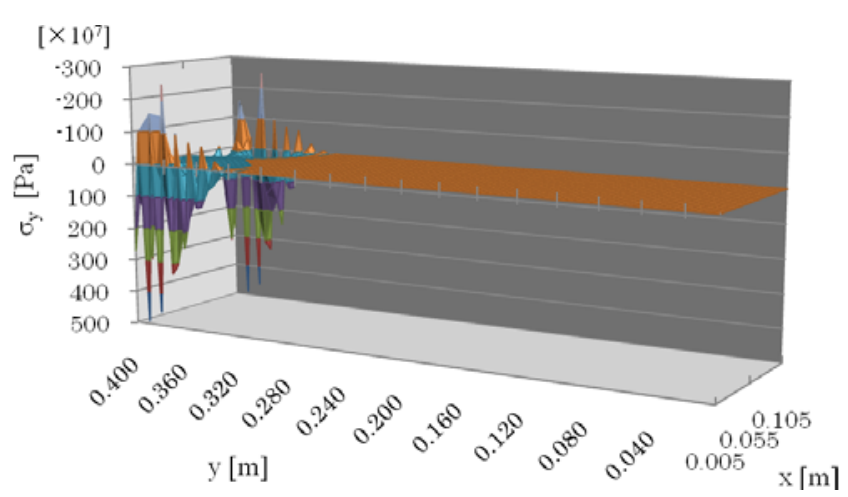

Fig. $2 \sigma_{y}$ stress distribution by traditional SPH equation 


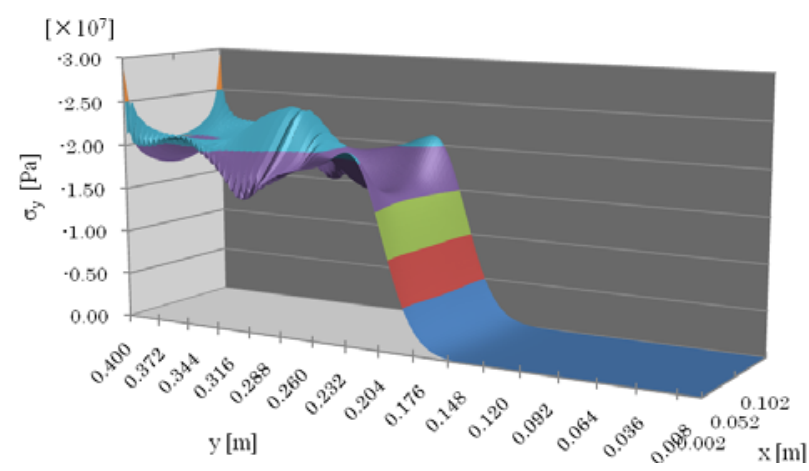

Fig.3 $\sigma_{y}$ stress distribution by hybrid SPH method $(\mathrm{t}=37 \mu \mathrm{s})$

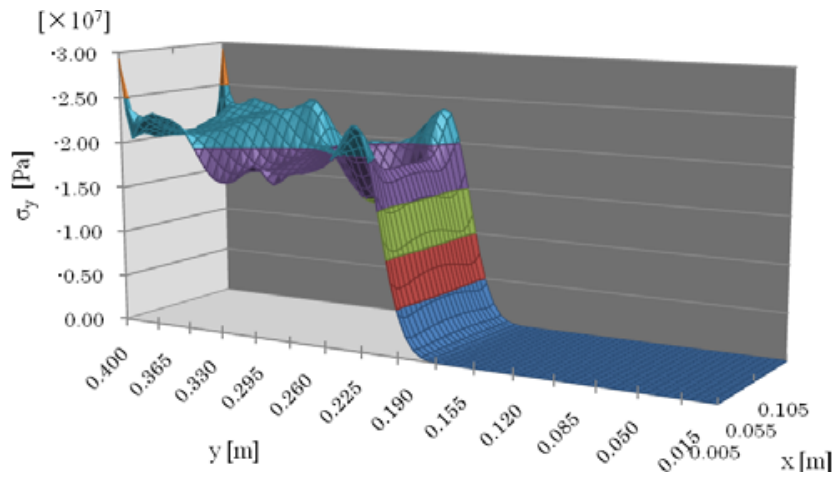

Fig. $4 \sigma_{y}$ stress distribution by MSC.Marc2007(t=37 $\mu$ s)

\section{ほぼ一致する。}

図 5 に SPH と FEM による板の中央部における応力 $\sigma_{\mathrm{y}}$ の分布を比較して示す. 応力波は図の右から伝播する. SPH は分割 $21 \times 83$ の場合と $51 \times 203$ の場合であり，FEM は $20 \times 80$ の場合である. 図示しないが FEM では 50 ×200 分割でも $20 \times 80$ の場合とほとんど違いがなかった．SPH の場合は FEM に較べ $2.5 \times 2.5$ 倍の分割にしても 数值拡散が大きく，精度は良くない.

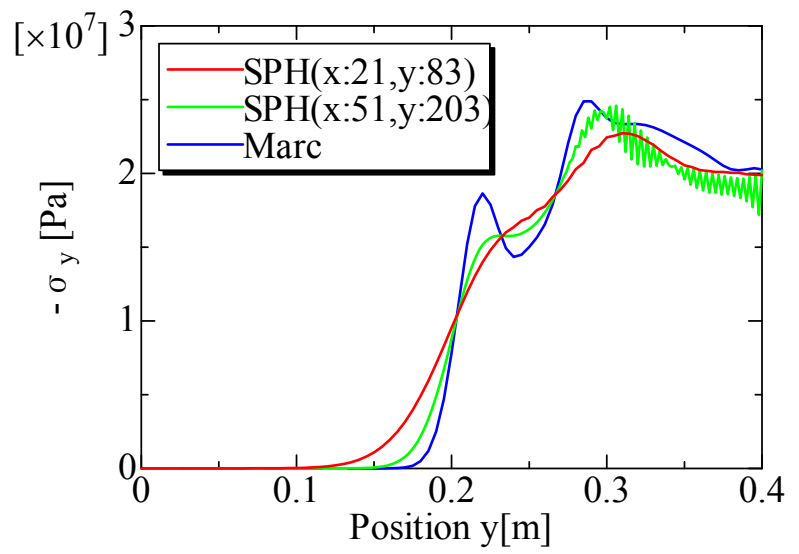

Fig.5 Comparison of $\sigma_{y}$ stress distribution at the center of the plate by hybrid SPH method and FEM ( $\left.\mathrm{t}=37 \mu \mathrm{s}\right)$

以上のように, 従来の SPH 法では端末効果のために弾性変形問題の解析は困難であるが，ハイブリット SPH 法を用いれば解析できる，ハイブリッド SPH 法では，従来の SPH 法と同じく固定境界には固定粒子を用いる必 要があるが，自由表面粒子を規定して応力值を与える必要がない.FEM と較べて精度が良くないが，これは今後 の課題である.

\section{$6 \cdot 2$ 異種金属接合板の衝撃問題}

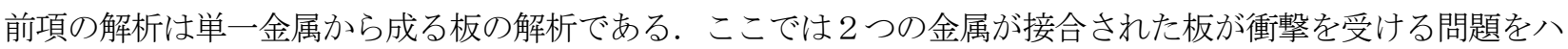
イブリット SPH 法で解析する.

物性值が異なる物質を同時に扱う場合，解析結果に大きな影響を与えると考えられる物性值として音速と密度 がある. そこで, 音速が大きく異なる $\mathrm{Fe}-\mathrm{Cu}$ 接合の場合と, 密度が大きく異なる $\mathrm{Fe}-\mathrm{Al}$ 接合の場合の解析を行う。 ここではまず，ハイブリッド SPH 法 I を用い，応力は緩和計算式(24), (25)を正規化して 2 相に跨って計算する.

図 6 に 2 種金属接合板の解析モデルを示す．また，表 1 に各金属の物性值を示す。このモデルの上部端面粒子 に一定速度 $v_{0}=0.5[\mathrm{~m} / \mathrm{s}]$ を与え, $y$ 方向に圧縮する. 底部は固定され，側面は自由表面である. $z$ 方向の応力は 0 と している. 
図 7 と図 8 に Fe-Cu の場合にハイブリッド SPH 法 I で解析した応力 $\sigma_{y}$ とひずみ $\varepsilon_{y}$ を示す. また, 図 9 と図 10 にMarcで解析した結果を示す．八イブリッドSPH 法 I による解析結果を Marc の結果と較べると，応力波面の 立ち上がりはハイブリッドSPH 法 I のほうが幾分緩やかで，また応力分布も幾分なだらかであるから，数值拡散 が大きいことが分かる．しかし全般にMarcの結果とほぼ同じ解析結果が得られた．図 8 や図 10 において, Fe 部分と $\mathrm{Cu}$ 部分のひずみが大きく違うのは $\mathrm{Fe}$ と $\mathrm{Cu}$ のヤング率 $E$ 及び風性率 $G$ の違いによるものである.

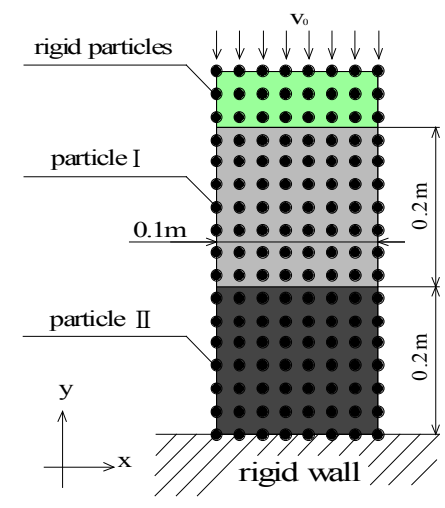

Fig.6 2 dimensional impact model of plate jointed by two different metal plates

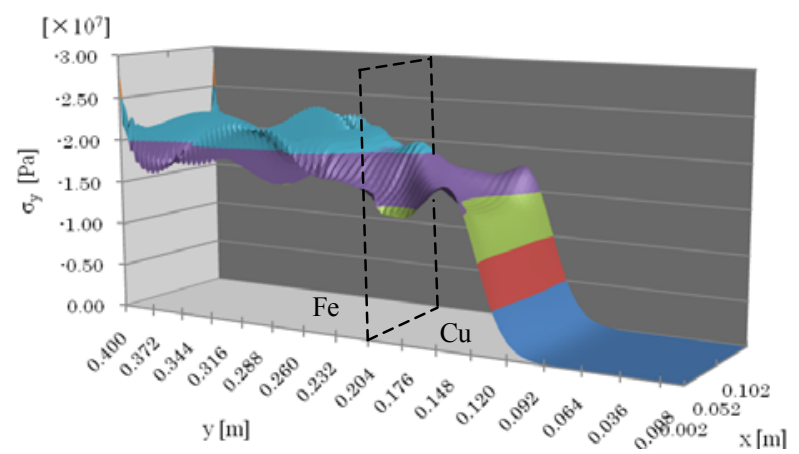

Fig. $7 \sigma_{y}$ stress distribution $\mathrm{Fe}-\mathrm{Cu}$ jointed plate analyzed by hybrid SPH method I $(t=57 \mu \mathrm{s})$

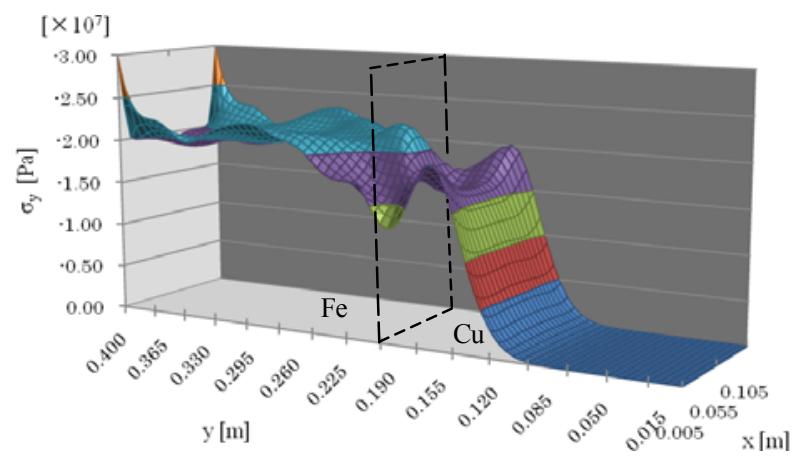

Fig.9 $\sigma_{y}$ stress distribution $\mathrm{Fe}-\mathrm{Cu}$ jointed plate analyzed by MSC.Marc2007( $t=57 \mu \mathrm{s})$
Table 1 Physical properties of materials

\begin{tabular}{|c|c|c|c|}
\hline & $\mathrm{Fe}$ & $\mathrm{Cu}$ & $\mathrm{Al}$ \\
\hline \hline$\rho\left[\mathrm{kg} / \mathrm{m}^{3}\right]$ & 7874 & 8920 & 2700 \\
\hline$E[\mathrm{~Pa}]$ & $206 \times 10^{9}$ & $123 \times 10^{9}$ & $70.3 \times 10^{9}$ \\
\hline$G[\mathrm{~Pa}]$ & $80 \times 10^{9}$ & $46 \times 10^{9}$ & $26.1 \times 10^{9}$ \\
\hline$v$ & 0.300 & 0.330 & 0.345 \\
\hline$C[\mathrm{~m} / \mathrm{s}]$ & 5115 & 3713 & 5103 \\
\hline
\end{tabular}

$\rho$ : density, $E$ : Young's modulus, $G$ : modulus of rigidity $v$ : Poisson's ratio, $C$ : sound velocity

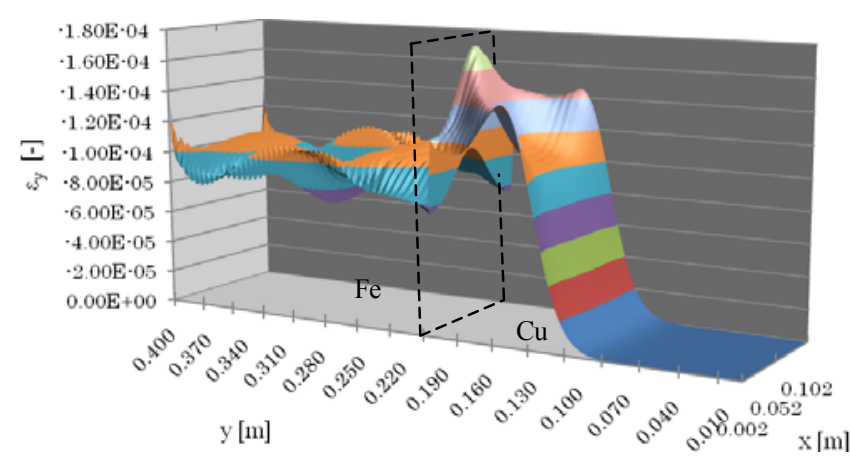

Fig. $8 \varepsilon_{y}$ strain distribution $\mathrm{Fe}-\mathrm{Cu}$ jointed plate analyzed by hybrid SPH method $\mathrm{I}(t=57 \mu \mathrm{s})$

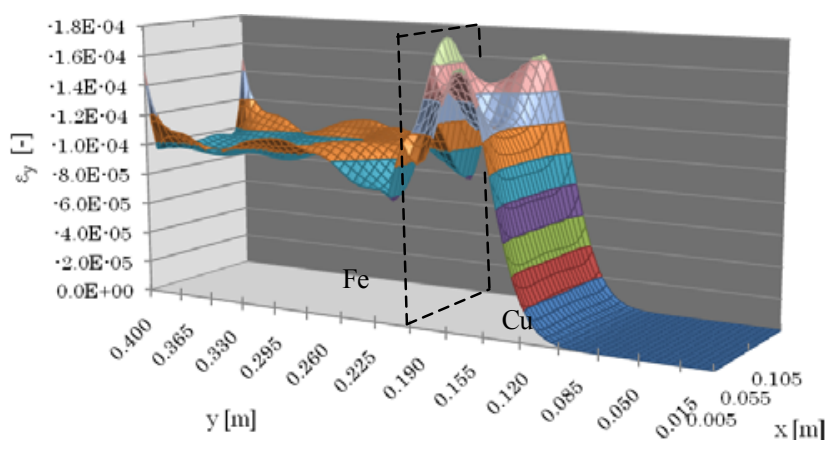

Fig. $10 \varepsilon_{y}$ strain distribution $\mathrm{Fe}-\mathrm{Cu}$ jointed plate analyzed by MSC.Marc2007( $t=57 \mu \mathrm{s})$

ハイブリッド SPH 法 I で解析した Fe-Al の場合の $\sigma_{y}$ と $\varepsilon_{y}$ の分布を図 11 と図 12 に示す. 図 11 の応力分布が図 7 に較べなだらかになっているが，これは図 7 では音響インピーダンス $\rho C$ が, $\mathrm{Fe}$ で $4.03 \times 10^{7} \mathrm{~kg} / \mathrm{m}^{2} / \mathrm{s}, \mathrm{Cu}$ では 3.31 $\times 10^{7} \mathrm{~kg} / \mathrm{m}^{2} / \mathrm{s}$ であり, その違いが小さいため, 接触部での応力反射は小さいのに対し, 図 11 では $\mathrm{Al}$ の音響イン 
ピーダンスが $1.38 \times 10^{7} \mathrm{~kg} / \mathrm{m}^{2} / \mathrm{s}$ と $\mathrm{Fe}$ に較べて小さく，鉄側に応力反射による除荷波が現れたためである．図 12 では $E, G$ の違いによりひずみ分布に大きな段差が見られる. 図 7,8 及び図 11,12 の自由表面近傍で応力と歪みが 小さく波打っているが, これは粒子の振動の影響と考えられる.

図 13 と図 14 に Fe-Al の場合の $\sigma_{y}$ と $\varepsilon_{y}$ をハイブリッド SPH 法IIで解析した結果を示す. 図 7 から図 14 まで は応力波が $2 つ の$ 金属の接触境界を過ぎて第 2 の金属を伝播する時の応力分布であるが, 図 13 と図 14 は応力波 が $2 つ の$ 金属の接触境界面に到達した直後の応力と歪み分布である. 境界で応力の振動が生じており, これ以降 はさらに振動が大きくなり計算不能となった. この振動は自由表面から内部に伝搬してきている. これは, 自由 表面近傍での $x$ 方向の歪の不整合により数值異常が生じたためと考えられる. 以上のことから, 異種金属が存在 する場合にハイブリットSPH 法 I を用いた解析の方が安定なことがわかる.

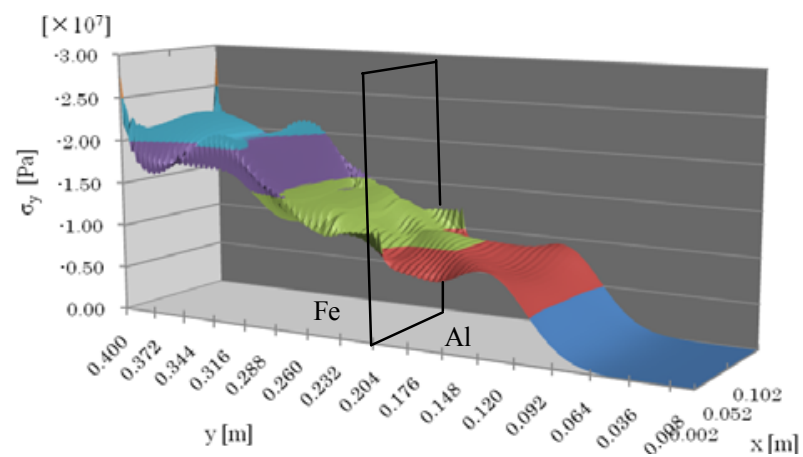

Fig.11 $\sigma_{y}$ stress distribution of Fe-Al jointed plate analyzed by hybrid SPH method $\mathrm{I}(t=57 \mu \mathrm{s})$

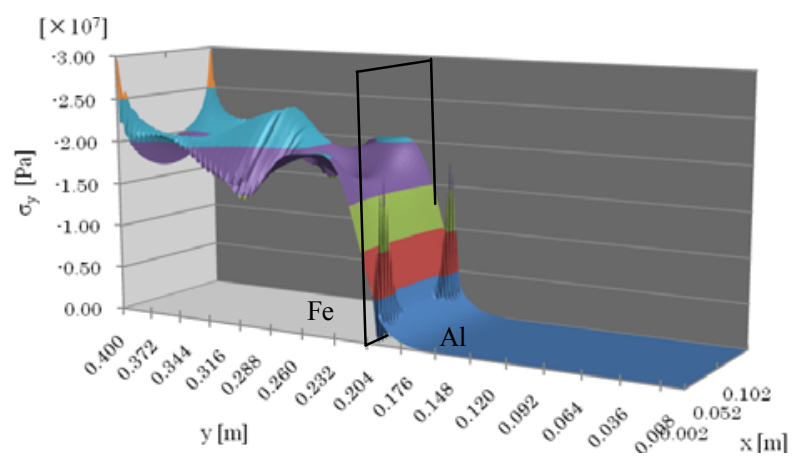

Fig.13 $\sigma_{y}$ stress distribution of Fe-Al jointed plate analyzed by hybrid SPH method $I I(t=37 \mu \mathrm{s})$

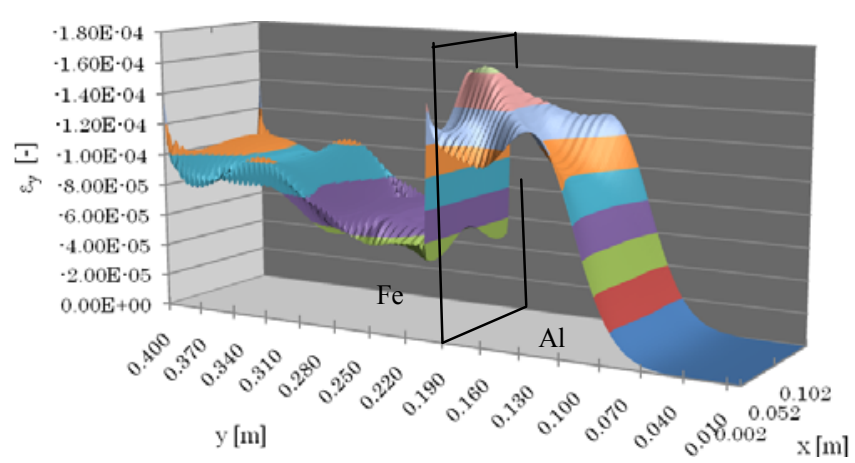

Fig.12 $\varepsilon_{y}$ strain distribution Fe-Al jointed plate analyzed by hybrid SPH method I $(t=57 \mu \mathrm{s})$

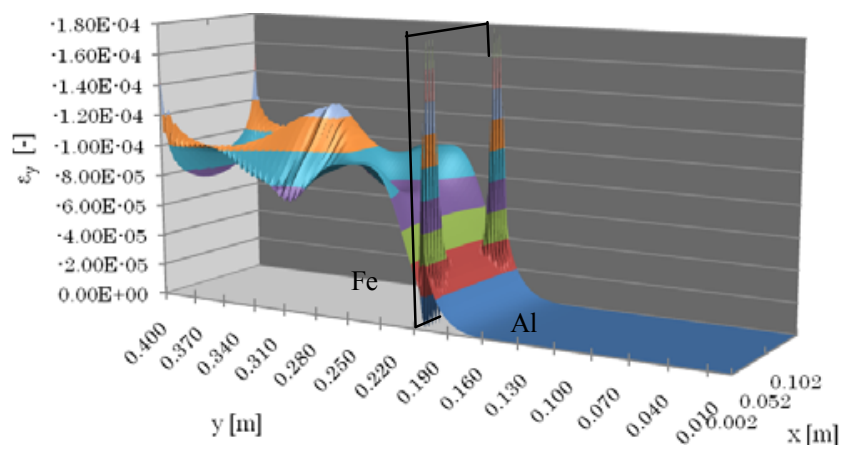

Fig. $14 \varepsilon_{y}$ strain distribution Fe-Al jointed plate analyzed by hybrid SPH method $\Pi(t=37 \mu \mathrm{s})$

\section{7. 結言}

接合金属の弾性挙動を各金属に分けることなくSPH 法で一括解析寸るために, 弾性体の緩和計算式を提案 した. また端末効果問題を避けるために粒子加速度を緩和計算式で計算し, 応力を, 緩和計算式を正規化し た NSPH 法で解析するハイブリッドSPH 法を提案した．2 次元薄板の弾性変形問題を解析し，これらの計算 法の有用性を示した.

なお，付言すると，本例の弾性解析では提案した解析法に較べ FEM のほうが精度が良く，解析時間も短いか ら，提案した解析法を用いる必要性がないと言えるが，本報告の目的は，FEM では取扱いが困難な大塑性変形問 題や衝撃破砕・飛散問題や，流体一固体連成問題を扱う上で必要となる弾性計算式を得ることにある. 


\section{参考文献}

(1) J. J. Monaghan: Particle Methods for Hydrodynamics, Computer Physics Reports 3, 71-124 (1985)

(2) L. D. Libersky, A. G. Petschek, T. C. Carney, J. R. Hipp, F. A. Allahdadi: High strain Lagrangian Hydrodynamics, Journal of Computer Physics, 109, 67-75 (1993)

(3) S. Hiermaier, D. Konke, A. J. Stilp, K. Thoma: Computational Simulation of the Hypervelocity Impact of Al-Spheres on Thin Plates of Different Materials, Int. J. of Impact Engineering, Vol.20, 363-374 (1997)

(4) H. Obara, J. Suemura and M. Honda : Fundamental Study of SPH Method (1st Report: Treatment of 2 Phase Flow), J. of Computational Science and Technology, Vol.2, No.1, 92-100 (2008)

(5) H. Obara, M. Honda, A. Koyama: Fundamental Study of SPH Method (2nd Report: Treatment of Two Phase Flow in Case of Different-size Particles), J. of Computational Science and Technology, Vol.2, No.1, 101-110 (2008)

(6) G. R. Liu, M. B. Liu: Smoothed Particle Hydrodynamics. World Scientific Publishing Co. Pte. Ltd. 315-316 (2003)

(7) P. W. Randles, L. D. Libersky: Smoothed particle hydrodynamics some recent improvements and applications, Computer Methods in Applied Mechanics and Engineering, No.138: 375-408(1996)

(8) H. Kolsky: Stress waves in solids, p.91, Dover publications, Inc. (1963) 